The systems engineering concept of digitalization of highereducation institutions (HEI) was proposed. The concept integrates the systemic, process-based, and project-based approach to displaying the objects and processes of the HEI activity in a unified digital space. This will make it possible to use it for automated solutions of functional problems in the educational, scientific, economic, and management processes of the HEI. Within the framework of the concept, the approaches to implementation were proposed: processes of the HEI digital transformation; functions and structures of the HEI digitalization project management; tools of a digital university. The concept is based on a unified digital space, which includes: digital and functional environment, tools for its formation, tools for using the digital environment. It was shown that the success of the transformation of the HEI into a digital university directly depends on the effectiveness of the organization of processes of digitalization project management. And this requires the use of the problem-oriented methodology of project management; the creation of a special division of the HEI digitalization; the development of the structure and technology of filling and using the digital space of an institution of higher education.

The result of the application of the HEI digitalization concept is the creation of the specified methodology for project management, which is focused on the digital transformation of an institution of higher education. New organizational principles of digitalization of higher education institutions were proposed, based on the project-oriented organizational structure - a digital transformation office. The structure and the functions of such an office were determined.

The processes of higher education institutions from the positions of readiness for the implementation of the systems engineering concept of digitalization were explored. Examples of the HEI digitalization using the proposed concept were given

Keywords: digitalization, project management, organizational structure, digital transformation, systems engineering
UDC 001.8:005.7:378

DOI: $10.15587 / 1729-4061.2020 .219260$

\section{DEVELOPING A SYSTEMS ENGINEERING CONCEPT FOR DIGITALIZING HIGHER EDUCATION INSTITUTIONS}

I. Teslia

Doctor of Technical Sciences, Professor Department of Technology Management National Aviation University Liubomyra Huzara ave., 1, Kyiv, Ukraine, 03058 E-mail: teslyas@ukr.net

N. Ye horchenkova

Doctor of Technical Sciences, Associate Professor Department of Project Management Kyiv National University of Construction and Architecture Povitroflotsky ave., 31, Kiyv, Ukraine, 03037 E-mail: realnata@ukr.net I. K h levna

Doctor of Technical Sciences, Associate Professor* E-mail: yuliya.khlevna@gmail.com

Y. Kat a ieva

$\mathrm{PhD}$, Associate Professor Department of Software of Automated Systems Cherkasy State Technological University Shevchenka blvd., 460, Cherkasy, Ukraine, 18006 E-mail: kataevae@ukr.net

T. La t y sheva $\mathrm{PhD}$, Assistant* E-mail: latysheva550@gmail.com

O. Yehorchenkov $\mathrm{PhD}$, Associate Professor* E-mail: alexee@ukr.net

A. KhIevny i $\mathrm{PhD*}$

E-mail: andlev@ukr.net V. Vere te In y k $\mathrm{PhD}$

Department of Information Technology The Bohdan Khmelnytsky National University of Cherkasy Shevchenko blvd., 81, Cherkasy, Ukraine 18031

E-mail: veretelnyk.vitaliy@gmail.com *Department of Technology Management Taras Shevchenko National University of Kyiv Volodymyrska str., 60, Kyiv, Ukraine, 01033

\section{Introduction}

The world is developing faster and faster. The volume of information is increasing. In most spheres of human activity, there is a shortage of specialists, especially with higher education. That is why to become a professional in one's field, it is necessary to gain more and more knowledge in the shortest possible time. This is impossible without intensification of the educational process, without enhancing the quality of the activity of higher education institutions, especially in the sphere of organization of the educational process, its provision with necessary resources, in particular, with information resources. 
The world trends of the development of society, education, science, and economics are aimed at the transition to digital transformation. In fact, this means that all processes of social, educational, scientific, entrepreneurial, and other activities completely transfer into the digital environment. It is for this purpose, first of all, that digitalization of higher education institutions is required. Digital universities need to be created. This is a requirement of time, a requirement of the country, a requirement of students. The COVID-19 pandemic showed that without digital transformation, a higher education institution is unable to organize a high-quality educational process, to organize remote work with documents of its units, and to function properly, which adversely affects students, teachers, employees.

That is why the issue of HEI digitalization comes to the fore in all projects of development and modernization of higher education. Much is done and was done in this regard. Information technologies of training, management, accounting, etc. are developed and were developed, but in most cases, these are disparate tools that are not combined into a single system for solving functional problems of the HEI. Such an organization corresponds to the local (task scheduling) approach when separate software tools that have their own information bases are developed (or purchased) for each functional problem. The systemic approach is not implemented - all the tools and components of data storage, processes of its filling and digitalization projects should be a unified system of the creation of digital universities.

That is why questions arise. What steps are necessary to be made to create an effective digital university? How to use system engineering for the HEI digitalization under modern conditions in order to create a digital university?

Finding an answer to these questions requires, at the first stage, the development of such a concept of digitalization, which would take into consideration the need for systemic integration of various approaches to the digitalization of higher education institutions. Of course, it would be possible to borrow the experience of the developed countries in the field of digitalization of universities. However, there is a problem associated with differences in the organization of higher education management in different countries, with the level of readiness of the HEI for digitalization, and availability of ready-made tools for the HEI digitalization. Moreover, even in the developed countries, there remains one quite significant drawback in the HEI digitalization. Most often, the HEI digitalization is considered as the process-based approach as an operational activity of a university, which does not allow complete involvement of the project management tools to increase the level of goal setting and goal attaining in the course of the creation of digital universities.

That is why there is a relevant scientific task, which is to develop such a concept of digitalization of higher education institutions, which would integrate the systemic, process-based, and project-based approaches to create the methods, models, and practical tools for the development of digital universities.

\section{Literature review and problem statement}

Paper [1] presents the research into information technologies in education and their implementation into the educational process and the system of management of an educational institution. However, the issues related to the formation of a class of technologies that support complex or partial processes and the HEI facilities remained unresolved.

The option to overcome the appropriate difficulties may be the use of ready-made software products that are presented in the market, for example:

- software products of automation of the process of creation and management and examinations of MedMe, BeAxi from KindGeek, (England) [2];

- systems of the management of the educational process for higher educational institutions "Directive", (Ukraine) [3]; - package of programs "Dean's office", "PS-EURODIPLOMA", "PS-Applicant", "Colloquium”, "Bibliographer", "PS-Staff" from Polytech-SOFT, (Ukraine) [4];

- software for the development of the system of accounting the student body Lotus Notes/Domino from IBM, (USA) [5];

- and others.

However, the experience of using ready-made software products impersonates the introduction of separate information systems for the HEI. The typical tools are created by different developers, they do not have a unified digital environment and necessary technologies for integrating various databases that use information from other systems. At the same time, ready-made software products do not create a unified system of the HEI management processes, do not cover all objects and processes of the HEI activity, and do not take into consideration the peculiarities of a particular university, while additional settings require further investments. Impersonation of a unified system of management of the HEI processes, which minimizes the disparity of systems, is presented in paper [6]. Functional modules and sub-modules of management of departments, educational courses, staff and students, communication tools, and reporting were singled out. This approach enables all the HEI stakeholders to perform and control their tasks. However, the issue of data implementation into the single digital environment of a university remains open.

That is why it is necessary to carry out the digital transformation of the HEI in order to create a digital space, which will become the foundation for solving functional problems in the educational, scientific, economic, management, and other spheres of higher education institutions.

The theoretical model of digital transformation implementation in the HEI is presented in research [7]. However, the issues related to the systemic digitalization of objects and processes of the HEI activity remained unresolved in the research. Besides, the presented model does not take into consideration the element of resistance in the implementation of new processes, which are distinguished in article [8] in terms of the creation of a digital university. In addition, as it is known from [9], the solution is to increase the level of technological maturity of institutions, to form influences on institutions for the effective implementation of the new methodology [10]. Moreover, with the digital transformation of the HEI, it is appropriate to take into consideration structural, budgetary, or cultural limitations, so it is advisable to use the flexible approach proposed in paper [11]. This approach will make it possible to adapt to changes with minimal costs.

The guidelines for creating a digital university, which are given in article [8], are up to the point:

1. Digital transformation affects every part of a university, rather than only IT. 
2. It is necessary to link all digital activities of a university to the general vision and strategy of a university.

3. It is necessary to invest in the communities, built around willing and capable digital innovators.

4. Accept the project approach focused on the needs of a customer, rather than the internal structure of a university.

Such advice will help to find the best options in solving the problems of the HEI digitalization in the creation and application of a digital university, but such advice should have some methodological basis.

The methodological concept of creating a digital university is proposed in paper [12]. In particular, the conceptual foundations of management of the HEI digitalization were presented. The effective management of the HEI digitalization was shown to be possible with the application of the "project management" approach. However, the issues of creating a digital space, which is separated from the functional tasks of the HEI, which are subject to automation, and acts as an independent system-forming component of the digital HEI, remain open.

Taking into consideration the above, we can conclude the importance of the scientific and practical significance of the systems engineering approach to the HEI digitalization. This approach combines the definition of HEI processes, their effective management in the digital environment, and the use of this environment for automated solving of functional problems of the HEI. Accordingly, it is proposed to develop a systems engineering concept of the HEI digitalization, which will reflect the processes, functions, structures, and tools for managing the HEI digitalization projects and present the use of such a concept under real conditions of higher education institutions.

\section{The aim and objectives of the study}

This research aims to create a systems engineering concept of digitalization of higher education institutions, which would integrate the systemic, process-based, and project-based approaches to solving the problems of creating digital universities.

To achieve the goal, the following tasks were to be solved:

- to state the problems of digitalization within the framework of the systemic, process-based, and project-based approaches, the solution of which will make it possible to create digital universities as a unified system of organizational, functional, and information components;

- to create the structure and implementation mechanisms of a digital university using systemic, process-based, and project-based approaches;

- to use the project-based approach to manage the creation of the digital space of the HEI;

- to implement practically the developed concept of the HEI digitalization.

\section{Problems of digitalization within the framework of the systemic, process-based, and project-based approaches}

Definition 1. The purpose of digital transformation is to enhance efficiency and quality of the HEI activities through the introduction of new technologies of activity, which are based on more complete and timely satisfaction of employees' needs for information by storing necessary information digitally in databases and knowledge bases of modern computers.

Definition 2. Information space of the HEI is the information received or formed in the HEI, and which is necessary to solve the functional problems of a higher education institution.

The result of digital transformation is the creation of the digital space of the HEI.

Definition 3. Digital space (DS) is the digital information storage, software tools for maintaining these storages that are implemented in computer facilities, and the organizational infrastructure that ensures the functioning of this space.

Based on definitions 2 and 3, information space is a broader concept than digital space. Some elements of the information space are digitized and transferred to the digital space, which, in turn, is a part of the HEI information space.

In addition, it follows from definition 3 that two components are separated in the digital space - the information environment of the DS and the functional environment of the DS.

Digital transformation aims to create a digital space, and therefore, to construct an informational and functional environment of the DS.

The fundamental difference between this concept of the digital transformation of the HEI and the concepts based on the local (task scheduled) approach is that the problem of creating the digital space is separated from functional problems. These are the problems that are subject to automation and act as an independent system-forming component of the digital HEI (Fig. 1). That is why this concept was called systems engineering concept.

Based on this statement of the HEI digitalization problem, it is necessary to solve three system-forming problems to achieve the set goal (definition 1):

1. To apply the process-based approach to the digital HEI transformation. This means that it is necessary to separate the main processes and to create a system of their management in digital transformation.

2 . To apply the project-based approach to the management of digital HEI transformation. This means that it is necessary to distinguish separate projects and create a system for their management for the effective management of digital transformation.

3. To apply the systemic approach to the structure and functions of the digital space of the HEI. This means that it is necessary to create the informational and functional environment of a digital university and to construct the tools for solving functional problems based on them.

Thus, in order to proceed from the concept based on the local (task scheduled) approach to the creation of a digital university to the systems engineering concept, it is necessary to combine the systemic, process-based, and project-based approaches into a single tool of the HEI digitalization (Fig. 1). Combining these approaches is the basis for the systems engineering concept of creating a digital university. Consider them based on the problems that are solved using the following approaches: systemic - product; process-based and project-based - product creation; project-based - product creation management. 


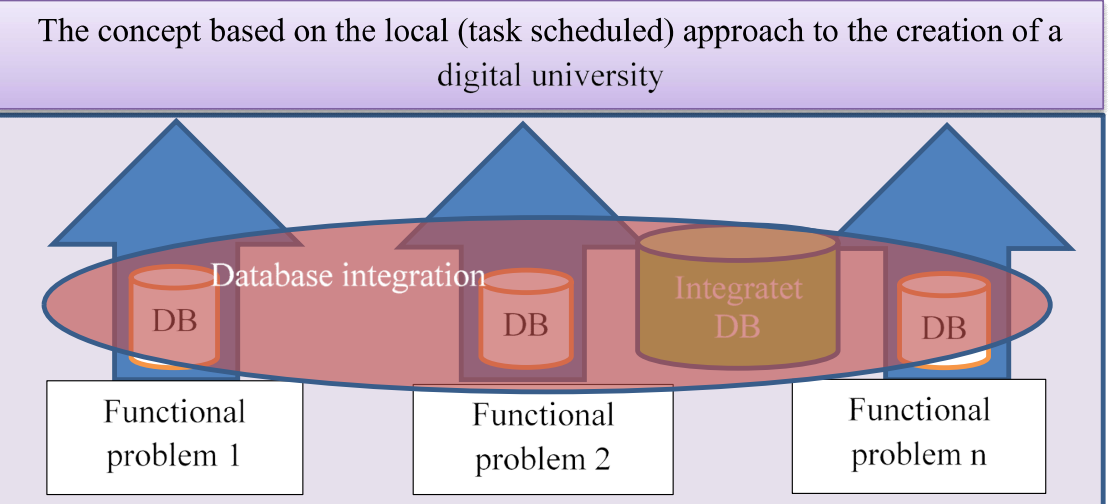

AIS HEI

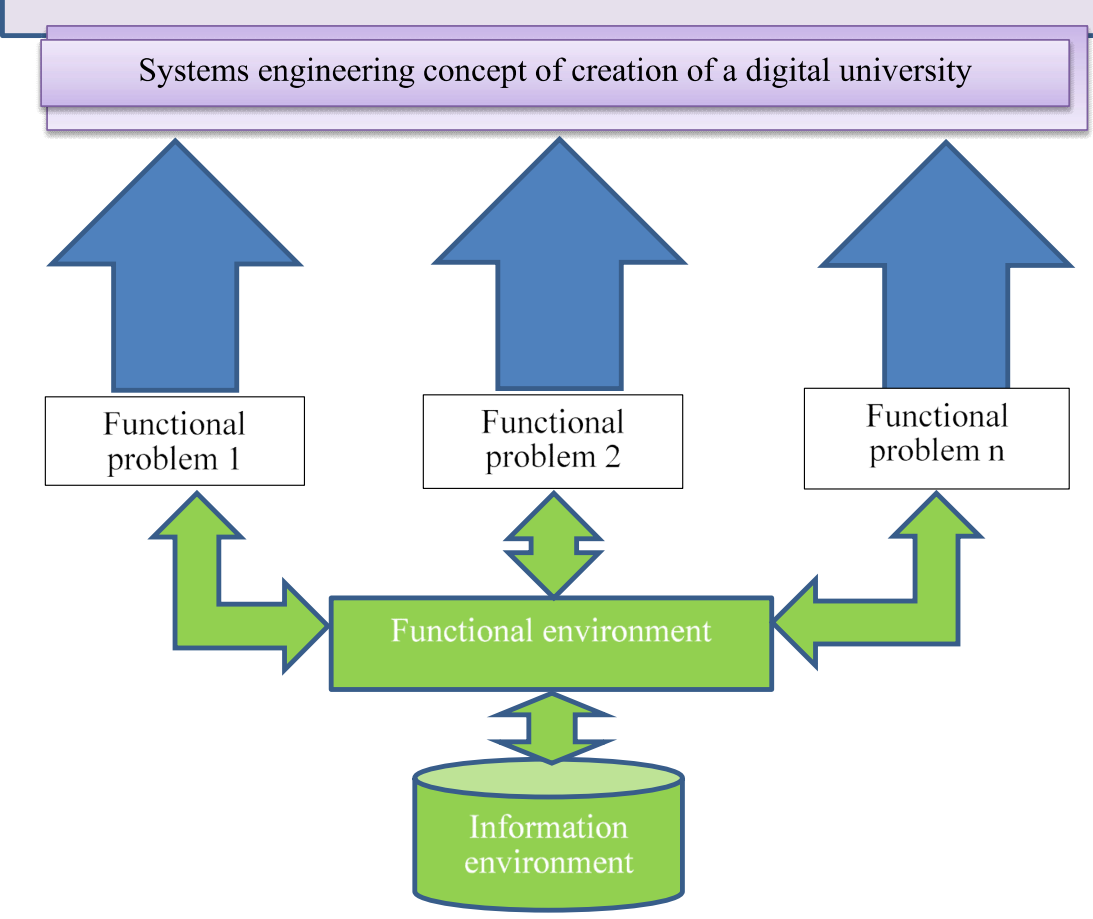

Fig. 1. The systemic approach to the digital transformation of a higher education

For example, incoming documents that are informative or regulatory by nature, which pass the clerical office, are sent (assigned) to stakeholders and stored in the archives.

2. Documents entered into the separate fields of databases through pre-base processing for the purpose of their further automated processing. In this case, using software tools, it is possible to use separate data of these documents for solving various problems. For example, curricula, from which educational load is formed.

Based on this, the ways of forming the information environment include:

1. Processing original documents with the help of special tools that ensure the entry of their details into the information environment through the user's interface.

The process approach is the main one. The tools for processing original documents should form an "information conveyor", which recycles the information resource in the form of paper documents (sometimes of the low quality of filling) into an information product (electronic document). This function must be performed using electronic processing of original documents. Moreover, to improve the efficiency of this work, employees who will perform this function must be concentrated in one unit and be in one place in order to increase their professional level, to ensure interchangeability when working on such an "information conveyor".

2. Formation of the information environment by means of solving functional problems realized in the processes of management, organiza-

\section{Using the systemic, process-based, and project-based} approaches to create the digital space of the HEI

5.1. Using the systematic approach to create the structure of the digital space of the HEI

To create the digital space of the HEI, it is necessary to determine exactly what documents, what data, and what functions should be included in the information and functional environment in order to get the maximum effect of such space. Traditionally, all databases are divided into factographic and documentary.

However, digital space requires shifting accents towards documentary databases (because in most cases whole documents are digitized and entered into a computer). Even when processing input information and entering it into a computer, it is also important that a database should be presented in the form of documents.

To enable a user to get it in its original form at any time, we will divide the documents that will be entered into the digital space into two categories:

1. Digitized documents that imply the program use of the separate elements (data) (in particular, the pdf format). tion, and implementation of educational, scientific, economic work, and international cooperation. The output information is not only provided for further application to a user but also is uploaded to the information environment.

A systemic approach is implemented. The means of solving functional problems in the creation of the digital space of the HEI should not only provide information to its consumers but also to form the information environment. For further use of this information, both at the request of the HEI employees, and to create an information standard of a higher education institution, which is a system of information that reflects the capabilities and actual assessment of the activities of units and employees in solving functional problems.

3. Displaying the information used in various processes and communications in the information environment. For example, the process of forming and controlling the execution of assignments or student-teacher communication, which are aimed at assessing the student's knowledge or providing him/her with educational information. In this case, information about these processes or interactions becomes a part of the information environment of the HEI and forms its information standard. 
The process approach is implemented. The processes of information interaction and flows of documents, assignments, approvals, and comments to documents, appeals, and responses to appeals are displayed. This is usually implemented based on some HEI information management platform, which provides electronic document flow, control of execution of assignments, digital archives of documents, communication, electronic training, and knowledge control, etc.

4. Placement of information on the websites of the HEI and subdivisions. The content of the HEI sites and their subdivisions is aimed at informing participants of the educational process and external stakeholders about their activities. The function is the HEI popularization among entrants, parents, other organizations, and companies that may be interested in cooperation in the educational, scientific, or economic spheres.

The systemic and process-based approaches are implemented. This makes it possible to store and display not only current information but also keep the whole history of changes and additions, to record the results of information interaction with consumers of this information (the process-based approach) and to conduct analytical work), to clarify the needs for specific information, the results of its use by stakeholders (the systemic approach). In part, this content is formed automatically by the functional environment of the HEI. For example, the timetable of classes, curricula, the material of academic disciplines, etc. It is partially selected by specialists from the information space of the HEI.

That is why to construct informational and functional environments of digital space as systems for presenting and processing information, it is necessary to answer 2 questions:

1. What documents should be uploaded to the digital space?

Let the benefits of storing the $T_{j}$ type documents in a digital environment be equal to:

$$
S_{j}=\sum_{k}\left(p_{j k} \cdot D_{j k}\right)-Z_{j}-\sum_{k}\left(p_{j k} \cdot W_{j k}-D_{j k}\right),
$$

where $S_{j}$ is the expected benefits from storing type $T_{j}$ documents in a digital environment; $p_{j k}$ is the probability that document $t_{j k} \in T_{j}$ will be demanded by users; $D_{j k}$ is the expected benefits from using document $t_{j k} T_{j}$ in the HEI; $Z_{j}$ is the costs for storing type $T_{j}$ documents in the digital environment; $W_{j k}$ is the costs for the search for and the use of document $t_{j k} \in T_{j}$ that is not stored in digital environment of the HEI.

Then, documents, for which

$$
S_{j}>0
$$

should be stored in the digital environment

2. Will access to the data from these documents will be necessary for automatic processing in software tools?

Let us assume that

$$
t_{j k}=\left\langle\tau_{j k 1}, \tau_{j k 1}, \ldots, \tau_{j k l}, \ldots \tau_{j k m}\right\rangle,
$$

where $\tau_{j k l}$ is the data of document $t_{j k}$.

If the following condition is satisfied

$$
\begin{aligned}
& \sum_{k} \sum_{l}\left(p_{j k l} \cdot F_{j k l}\right)-X_{j}- \\
& -\sum_{k} \sum_{l}\left(p_{j k l} \cdot\left(V_{j k l}-F_{j k l}\right)\right)>0,
\end{aligned}
$$

where $p_{j k l}$ is the probability that data $\tau_{j k l}$ of document $t_{j k} \in T_{j}$ will be necessary for automatic processing in the functional environment of digital space; $F_{j k l}$ is the expected benefits from using data $\tau_{j k l}$ of document $t_{j k} \in T_{j}$ in the functional environment; $X_{j}$ is the costs for presentation and storing the $T_{j}$ type documents in the form accessible for automatic processing; $V_{j k l}$ is the costs for using external data $\tau_{j k l}$ in a functional environment, such document must be presented in the form accessible for automatic processing and entered into separate fields of the database.

Thus, to implement the systems engineering concept, it is necessary to create a system of documents, their data, the functions of their processing, and the data obtained during processing. In fact, it is necessary to create a system of information - an information environment and a system of functions - a functional environment.

The model of data and functions that corresponds to formulas (1) and (2) and makes it possible to provide the systemic-technical basis of digital space is proposed. Schematically, such systems are shown in Fig. 2 (explanation Table 1) and include the following elements:

1. Information environment:

1.1. Archives of documents: scanned documents of the documentary database.

1. 2. Original accounting and management documents: records, registers, reports, group registers, etc.

1.3. Documents on education: diplomas, certificates, supplements to diplomas.

1.4. Incoming documents: all documents submitted to the clerical office of the HEI, including citizens' appeals.

1. 5. Data that reflect the information space of the HEI: staffing, departments, authorities, contacts, etc.

1.6. Documents on activities: documents necessary for international, economic, scientific, management activities.

1. 7. Documents about students: grades, acknowledgments, and punishments, accommodation in dormitories, participation in competitions, olympiads, artistic activity, sporting events, academic mobility, student self-government, etc.

1.8. Documents on the educational process: examination records, scoring books, and other reports, attendance registers, etc.

1. 9. Information from UDEBE: information about students and teachers.

1. 10. Curricula and working curricula: disciplines, types of classes, work volumes.

1. 11. Educational materials: lecture notes, presentations, methodical instructions, manuals, textbooks, video lectures, etc.

1. 12. Annual educational load: educational load per one academic year in the context of departments.

1. 13. Educational load of teachers: educational load for an academic year individually for teachers.

1. 14. Orders, Instructions, Contracts.

1.15. Educational files: files containing lecture notes, presentations, guidelines, manuals, textbooks, video lectures, etc.

1. 16. Plan of the educational process: schedule of the educational process, timetable of classes.

1. 17. Syllabi: a formal description of disciplines.

1.18. Official notes, reports, and other internal documents.

1. 20. Financial information: budget, applications, funds flow, expenses of subdivisions, funds, etc. 
1. 21. Financial and accounting documents: incoming documents of accounting and management records (invoices, payments, timesheets, registers, reports, requirements, contracts, etc.).

1. 22. Content of sites of the HEI and its subdivisions: factual information posted on the websites of the HEI and its subdivisions.

2. Functional environment:

2. 1. Curricula and working curricula; documents on the activities of students; USEBE $\rightarrow$ Annual educational load: the function takes into consideration the contingent of students in the amount of educational work, which makes the educational load of a university.

2. 2. Annual educational load; data that reflect the information space of the HEI; USEBE $\rightarrow$ Educational load of teachers: the function uses the annual educational load, which is distributed based on the information about departments and teachers from the information space of the HEI and USEBE.

2.3. Curriculum and working educational plans; syllabi; USEBE; educational files $\rightarrow$ Educational materials: the function, based on the disciplines of the curriculum, the content of syllabi and students' participating in educational programs gives access to educational materials stored in various files to students of the HEI. In fact, it is the function of students' education and knowledge control.

2. 4. Documents on the activities of students; documents of the educational process; plan of the educational process; USE$\mathrm{BE}$; archives of documents $\rightarrow$ Documents on education: the function forms the documents certifying the motion and evaluation of a student on the trajectory of the educational process.

2.5. Educational load of teachers; documents on the activities of students $\rightarrow$ plan of the educational process: the function forms the timetable of classes; the schedule of practices and preparation of diploma works.

2.6. Plan of the educational process; documents on the activities of students; orders, instructions, contracts; official notes, reports, and other internal documents; USEBE $\rightarrow$ Electronic dean's office: the function creates new information about students' education supplementing the planned information with the operative (flow of the students' educational process) and regulatory (including orders for students).

2.7. Financial and accounting documents; archives of documents $\rightarrow$ Accounting and management records: the function of information support of accounting systems by means of pre-base processing of original documents.

2. 8. Financial and accounting documents; official notes, reports, and other internal documents; archives of documents $\rightarrow$ Financial information: the function provides a selection of financial information, its representation in a form convenient for users, or in the one that must be uploaded to information systems.

2. 9. Incoming documents; orders, instructions, contracts; official notes, reports, and other internal documents; documents on education; accounting and management records; financial information; database of documents on activities $\rightarrow$ Archives of documents: the function of entering digital space scanned documents received or created during the implementation of functions into the archives of digital space.

2. 10. Documents on activities; an archive of documents $\rightarrow$ Base of activity documents: the functions of display- ing documents on educational, scientific, and other activities in the digital space. It can be plans, reports, tasks, normative documentation regulating the type of activity, etc.

2. 11. Functions of providing employees and authorities of the HEI with information from the digital space and information systems. Functions search for necessary information, its presentation in the desired form, and transfer of the received information resource to the Consumer (the HEI authorities, the HEI staff, information systems) at the request of a user or the HEI authorities:

- annual educational load $\rightarrow$ Consumers;

- documents on education $\rightarrow$ Consumers;

- educational load of teachers $\rightarrow$ Consumers;

- plan of the educational process $\rightarrow$ Consumers;

- accounting and management records $\rightarrow$ Consumers;

- financial information $\rightarrow$ Consumers;

- digital dean's office $\rightarrow$ Consumers;

- archives of documents $\rightarrow$ Consumers;

- database of activity documents $\rightarrow$ Consumers;

- educational materials $\rightarrow$ Consumers.

2.12. Functions of formation of content of the HEI sites and subdivisions. These are external functions of the functional environment. Their implementation provides information to all entities of the HEI. The functions search for necessary information in the information environment, its presentation in the desired form, and upload the received information resource to the sites of the HEI and subdivisions. Implemented in 2 modes. Automatically - after the appropriate configuration of the functional environment. Selectively - with the participation of HEI employees who implement relevant requests or perform analytical work on information from the digital space. Almost all elements of the information environment can be used. Exclusions are personal data:

- curricula and working curricula $\rightarrow<$ automatically $>\rightarrow$ Content;

- documents on students' activity $\rightarrow<$ selectively $>\rightarrow$ Content;

- annual educational load $\rightarrow<$ selectively $>\rightarrow$ Content;

- plan of educational process $\rightarrow<$ automatically $>\rightarrow$ Content;

- digital dean's office $\rightarrow<$ selectively $>\rightarrow$ Content;

- base of documents on the kinds of activity $\rightarrow<$ selectively $>\rightarrow$ Content;

- educational materials $\rightarrow$ Content;

- documents on the kinds of activity $\rightarrow<$ selectively $>\rightarrow$ Content; tent;

- data from information space $\rightarrow<$ selectively $>\rightarrow$ Con-

- incoming documents $\rightarrow<$ selectively $>\rightarrow$ Content;

- orders, instructions, contracts $\rightarrow<$ selectively $>\rightarrow$ Content.

2. 13. The functions of information processes and communications. The functions of providing the necessary information to the employees of the HEI in the modes: electronic document flow, control of the execution of assignments, digital archives of documents, and communications. These are internal functions of the functional environment, which ensure the implementation of all information processes and communications. These functions are implemented based on the platform of software information management. Ensure processing of all elements of the information environment. 


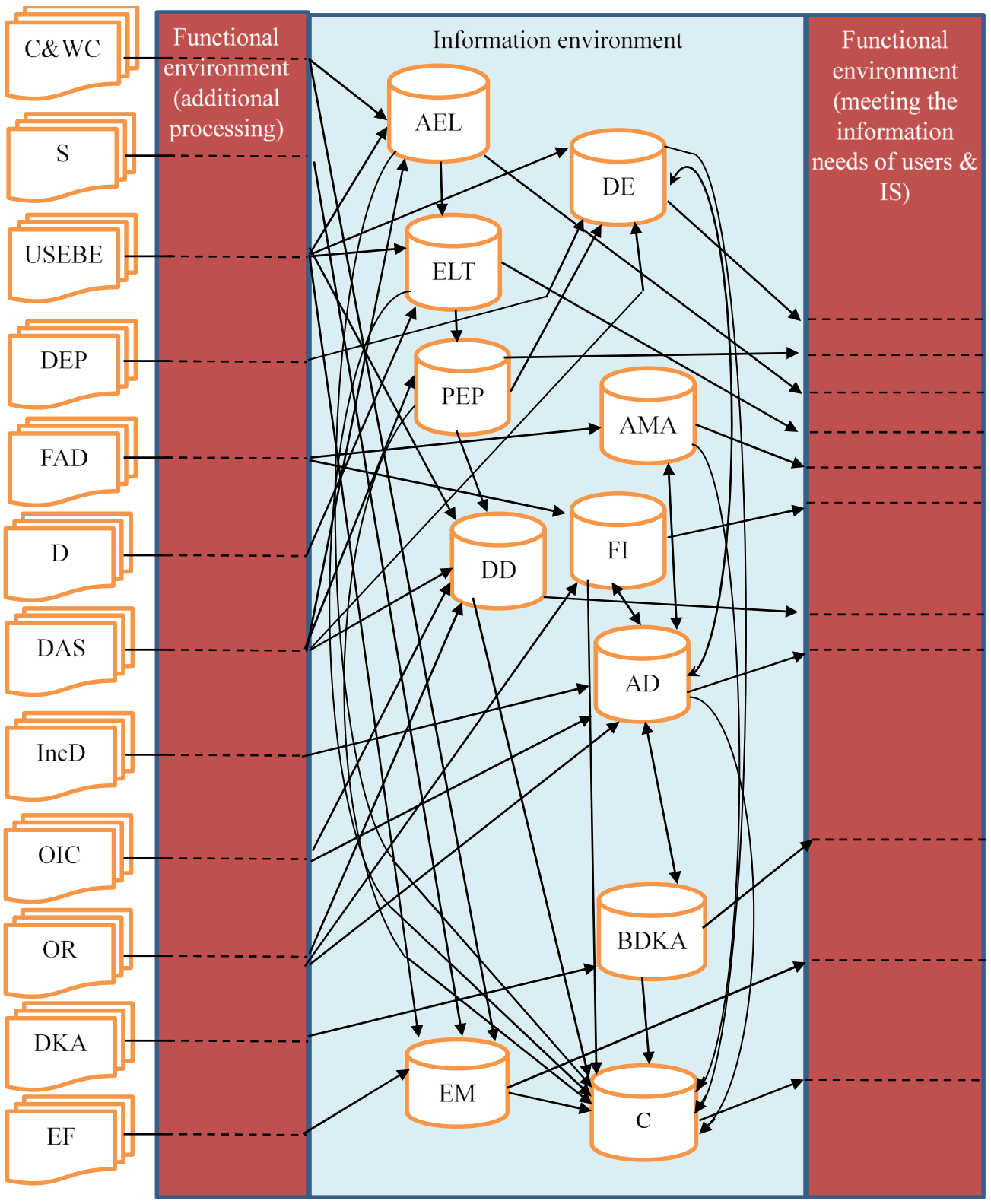

Fig. 2. The trajectory of information flow at a digital university

The main part of the functions of the functional environment is implemented within the educational process. In this case, the educational process is, on the one hand, a consumer of the information environment of the HEI. On the other hand, in accordance with the fact that the information environment is filled with the tools for solving functional problems, it forms the information content of this environment.

The functions of the functional environment aimed at the maintenance of the educational process are classified into two groups:

1. Functions of management of educational process (functions 1. 1, 1. 2, 1. 4, 1.5). They are aimed at providing teachers, students, employees of dean's offices and departments with information: work;

- regarding the volume and direction of educational

- personalization of responsibility for a discipline and carrying out of all types of educational work;

- on normative and legal support of the educational process;
- synchronization of the information of the HEI with the USEBE information;

- schedules and plans of classes and the forms of their conduct.

2. Functions of implementation of the educational process in the digital HEI (functions 1.3 and 1.6).

This is the function that ensures communicative teacher-student interactions and implements the process of forming the educational content of the site and the platforms used to teach students. Ensures educational work and control of students' knowledge. Typically, well-known platforms, such as Moodle, ClassRoom, MS Teams, etc., are used for this purpose. However, as the experience showed, the most appropriate requirements of the digital HEI are the Moodle system. Its advantages are:

- it is and it will be an open software platform, which was created and is being developed by thousands of software development specialists around the world;

- its database can be located on the HEI server and be physically a part of the information environment, which eas- 
ily makes it possible to integrate it with other parts of this environment;

- upon dismissal of a teacher, the access to this part of the information environment belongs to the HEI and cannot be blocked or destroyed by a dismissed teacher himself. When one tries to perform these steps, it can be recovered from a copy of the information environment and changes to the rights and passwords of the system administrator may be made.

\section{Explanation to abbreviations in Fig. 2}

\begin{tabular}{|c|c|}
\hline AD & Archives of Documents \\
\hline BDKA & Base of Documents on the Kinds of Activity \\
\hline AMA & Accounting and Management Accounting \\
\hline DE & Documents on Education (including supplements to diplomas) \\
\hline IncD & Incoming Documents \\
\hline D & $\begin{array}{c}\text { Data that display the information space of the HEI (staffing, } \\
\text { structure, archives, etc.) }\end{array}$ \\
\hline DKA & $\begin{array}{c}\text { Documents on the Kinds of Activity (international, economic, } \\
\text { scientific, and other kinds of work) }\end{array}$ \\
\hline DAS & $\begin{array}{c}\text { Documents on the Activity of Students (dormitory, competitions } \\
\text { and olympiads, academic mobility, performance) }\end{array}$ \\
\hline DEP & Documents of Educational Process (records, attendance) \\
\hline DD & Digital Dean's office \\
\hline USE- & Unified State Electronic Base on the problems of Education \\
\hline BE & Curricula and Working Curricula \\
\hline EM & Educational Materials \\
\hline AEL & Annual Educational Load \\
\hline ELT & Educational Load of Teachers \\
\hline OIC & Orders, Instructions, Contracts \\
\hline EF & Educational Files \\
\hline PEP & Plan of Educational Process (including the timetable of classes) \\
\hline S & Syllabi \\
\hline OR & Official notes, Reports, and other internal documents \\
\hline FI & Finformation (budget, bonuses, etc.) \\
\hline FAD & Cond the HEI sites and subdivisions \\
\hline C & \begin{tabular}{c} 
Finaunting Documents \\
\hline
\end{tabular} \\
\hline
\end{tabular}

The systems engineering properties of the above information and functional environments are based on:

- separation of certain components of the information space from the functional tasks of the HEI;

- integration into a single system in the digital space with the following use to solve functional problems and meet the information needs of students, teachers, and employees of an institution of higher education.

However, the integration process itself requires separating in the systems engineering concept of digitalization, the processes, and projects that will make it possible to form the digital space of the HEI. Consider the approaches to solving this problem.

\section{2. Using the process-based and project-based} approaches to create the digital space of the HEI

Consider the procedure and the tools for solving the problems of the HEI digitalization in terms of the process-based and project-based approaches.

1. The process-based approach to the digital transformation of the HEI. Implementation and management processes.

Digital transformation includes such implementation processes as:

- analysis of the information infrastructure of the HEI and creation of a model of information space of an institution of higher education;

- creation of the platform of digital space - the selection of tools and creation of databases for representation in computers of the information environment of the DS;

- digitalization of the information space;

- informatization of activity.

The processes of the digital transformation management processes are implemented based on the concept of "management through the project". That is why the project approach is very important for digital transformation.

2. The project approach to the management of the digital transformation of the HEI. Implementation of each of these processes can be presented as a totality of separate projects. All projects are incorporated into a unified program for the creation of a digital university (Fig. 3).
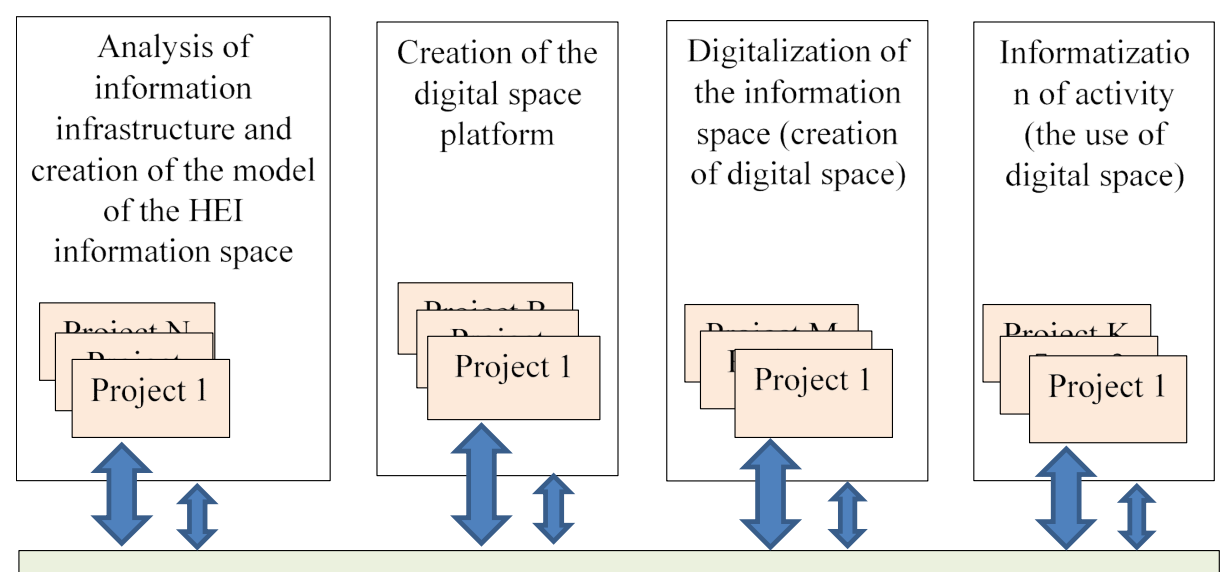

THE PROGRAM OF CREATING A DIGITAL UNIVERSITY

Fig. 3. The structure of the program of creating a digital university 
The projects themselves can be separated by the features given in Table 2.

The digitalization projects, which must be performed in the HEI in the context of the processes separated in Fig. 3 include:

1. Within the framework of analysis of the information infrastructure of the HEI and the creation of the model of the information space of the HEI, various projects are implemented. Specifically, the projects are aimed at researching the activities of HEI subdivisions, communications and documentation exchange flows, sources, and information consumers. In addition, the projects are classified in terms of the functional tasks of the HEI.

2 . Within the framework of the process of creating a digital space platform (feature - result), digitalization projects aimed at the development of the structures of databases and functions of information processing by means of DBMS and applied software tools are implemented. Examples include projects of:

- creation of databases;

- database integration;

- development of the functional environment in the form of DBMS functions or applied systems of the pre-base processing of information entering databases from applied software tools; - development of the DBMS functions or applied software tools for providing information from databases to apply software tools that solve functional problems.

3. Within the framework of the process of creating a digital space platform (featurefunctionality), there are digitalization projects aimed at filling the digital space with:

- normative and reference information;

- educational materials;

- description of the HEI infrastructure;

- information about the HEI activities;

- all archival documents (through digitization) used in the activities of the HEI and the access to which through the digital space will enhance the efficiency of employees.

4. Within the framework of the process of the information space digitalization (feature - the stage of development of the functional environment of the DS), the projects for the creation of the functional environment of the DS in the part of:

- actualization of regulatory and reference information;

- synchronization with the USEBE - information support of the educational process;

- management of the educational process;

- management of the HEI;

- information support of the HEI activities;

- actualization of information about students (including ensuring e-democracy);

- interaction with the system of electronic document flow.

5. Within the framework of the activity informatization process (feature - stage of implementation of information systems of the HEI), the following projects of creation of information systems are implemented:

- "university in a smartphone";

- digital dean's office;

- information management;

- distant learning;

- management of the educational process;

- management of the HEI;

- according to certain types of HEI activity (planning

and finance, economic, scientific, international, etc.);

- e-voting;

- electronic document flow;

- management of digitalization projects,

- etc.

Table 2

Features for classification of digitalization projects

Features for projects' classification

\begin{tabular}{c|c|l} 
Result & Functionality & Implementation stage \\
\hline
\end{tabular}

1. Description of $\quad$ The framework within

the information which the functions

infrastructure research is carried out

(educational process,

2. Model of the

information space $\begin{aligned} & \text { economic, scientific, man- } \\ & \text { agerial, international, etc.) }\end{aligned}$

1. Functions of

databases (for exam-

ple, the PostgreSQL

function)

In accordance with the

database classification

2. Applied program tools

-
In accordance with the
stages of development
of the functional envi-
ronment of the DS
in accordance with the
stages of implemen-
tation of information
systems of the HEI

In addition, the program of creation of a digital university includes the projects that implement the process of management of the digital transformation of the HEI.

These are the projects of:

- creation of an organizational structure specific to the HEI - a digital transformation office (modeled on the project management office) $[12,13]$;

- development of a methodology for management of the digitalization project that is specific for the HEI;

- creation of information technology for managing digitalization projects.

Consider the features of the implementation of these projects of digital transformation management.

\section{Using the project-based approach to manage the} creation of the digital space of the HEI

\section{1. The project of creation of a digital transformation} office

Typically, project management offices are created in project-oriented organizations [12]. The HEI is not a project-oriented organization. However digital transformation cannot be performed without separating the projects aimed 
at the digitalization of information space. That is why within the framework of the concept of digital transformation, it is proposed to create digital transformation offices (DTO).

Definition 4. A digital transformation office is a project-oriented structure, in which university officials perform different roles in the digital transformation program. In particular, these are the roles of a project coordinator, a digital space administrator, a project manager responsible for informatization in a subdivision, a developer, an instructor, a methodologist, a consultant, a methodologist, a technologist, etc. [12].

A digital transformation office is not a typical subdivision of higher education institutions. Based on the autonomy of the HEI, in terms of the formation of the structure and the staffing, a digital transformation office can unite such traditional subdivisions as information centers, a department of technical facilities and distance learning, etc.

A digital transformation office (DTO) should ensure the implementation of the classes of projects separated in Table 2. The DTO functions are professional provision and centralization of information exchange processes among the departments involved in the projects for:

- development of the concept of the HEI digitalization;

- planning and control over the implementation of digitalization projects;

- organization of project activity;

- recommendation for the role of the digitalization project managers;

- providing digitalization project managers with labor

- participation in the formation and expert evaluation of potential digitalization projects;

- initiation of digitalization projects;

- operative management of digitalization projects;

- management of development and development and implementation of digital transformation tools of the HEI;

- management of development and development and implementation of information systems and technologies for solving functional problems;

- support of the operation of implemented digital transformation tools and software tools of information systems for solving functional problems;

- development of methodological recommendations, instructions, manuals, and training users under conditions of digital HEI;

- creation of the digital space of the HEI.

6. 2. The project of development of a methodology for the management of digital transformation projects

After the creation of the DTO, there arises the problem: what managerial tasks and functions should office workers perform for the successful digital transformation of the HEI? The answer to this question can be obtained only from the specified methodology of project management oriented to the conditions of digitalization projects [10,14] (Fig. 4).
Meta-methodology PM

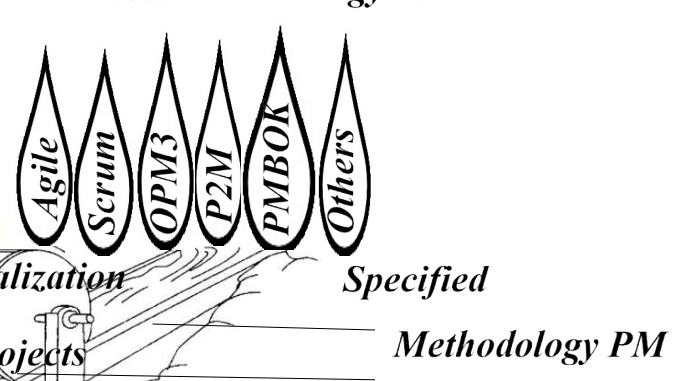

Methodology PM

This methodology should include the basis that makes it possible to clearly determine the purpose, goals, objectives, results of digitalization projects of the HEI. The specified methodology for managing digitalization projects should include management tools while minimizing risks, through in-depth analysis of digitalization problems and rational planning. Different project management methodologies were created by tens, hundreds, thousands of professional managers over several generations [15, 16], but none of them are suitable for the conditions of the HEI digitalization projects.

Flexible methodologies [10] do not take into consideration the specifics of the tasks of the HEI digitalization [11], and classical ones [12] require significant costs for the formalization of business processes of a University. That is why there is a problem of creating the methodology for the HEI digitalization projects - a specific methodology for project management [14].

In the formation of such methodology, it is necessary to take into consideration the internal and external processes of the HEI, the processes of project management, and the development of information technologies.

The structure of this methodology is proposed in paper [12]. However, taking into consideration the peculiarities of each HEI, it should contain a component of the organization of digital transformation management. In different HEIs, this task is solved in different ways so far. In addition, for digitalization projects, a combination, on the one hand, of the processes of managing the creation of digitalization tools, on the other hand, of the tools for managing individual digitalization projects, is relevant. That is why in addition to the structure of the methodology given in paper [12], it is proposed to use a matrix organizational structure of digitalization project management as the basic one (Fig. 5).

6. 3. Implementation of the information technology for digitalization projects management

Unlike the projects aimed at creating organizational (ODT) and methodological bases of digital transformation, the creation of information technology for project management differs little from the project of creation of information technologies for project management in other spheres of activity. It is necessary to use the tools, such as MS Project, Oracle Primavera P6 EPPM, or cloud services, such as Basecamp, Clarizen, Zoho, Wrike, and others. 


\section{Practical results of the creation of a digital university}

Implementing the above-mentioned systems engineering concept of digitalization in the program "National Aviation University - a digital higher education institution", the systemic, process-based, and project-based approaches to the creation of the tools for the creation and the use of the digital space of a university were implemented [12].

Within the framework of the program, the following systems and technologies for filling and using the digital space were developed:

1. Information environment. It is located on the servers of the NAU and includes 92 tables of the database (approximately 800 classes of objects).

2. Functional environment. About 200 functions of information transfer to the digital space and information transfer from the digital space to users and to information systems.

3. Electronic document flow system (PrimaDoc) (also as a tool for the formation of the digital space). It provides filling the digital space with incoming, outgoing, and internal documents (official notes, submissions). This means that all these documents are entered into the information environment, sent for consideration to the university authorities and heads of subdivisions. They are monitored by terms and routes of passage, stored in the archives, and become available for use via a WEB browser, both from the workplace and off the workplace. In total, since the beginning of the industrial implementation of the PrimaDoc system (October 2019 - June 2020), the following was uploaded to the information environment: incoming documents - 2,341, official notes - 1,564, assignments - 1,045, syllabi $-1,023$, e-mails - 937, certificates, memos, reports 854 , orders - 408, citizens' appeals - 305, internal letters - 197, other documents - 469.10,197 scanned documents were posted and 38,544 tasks were given.

4. The technology of agreement of syllabi of disciplines. The implementation algorithm is the following: the academic secretary of the department receives a syllabus from a teacher, makes a primary check, and uploads a doc (docx) file to the digital space. There are templates in the digital space regarding the order and the person who should agree on a syllabus. A syllabus is automatically sent to reviewers. A reviewer can agree on a syllabus, make technical changes, and agree or return to the academic secretary with comments. Upon return, all prior agreements are canceled. During the use of the technology (October 2019 - May 2020) 1,023 syllabi were agreed upon and uploaded to the digital space. The average time of consideration and agreement on syllabi decreased from 34.98 days to 12.46 days.

5 . The system of keeping records of academic mobility projects. It is intended for introduction, control over the implementation of academic mobility projects, entering the correspondence with stakeholders into the digital space, accounting, and control of students' participation in such projects. It has just been put into practice.

6 . The system of keeping the records of competitions of students' scientific works and olympiads "Student Science". All information on competitions and olympiads (venue, number of participants and prizes, etc.) is digitized, entered into the information environment, participants' records are kept, prize-winners and winners are recorded. Information on 65 competitions of scientific student works was uploaded to the digital environment. It regarded 123 participants in the second round of these competitions. In addition, information on 110 Olympiads and 230 participants of the $2^{\text {nd }}$ round was digitized. Information on the winners and prize-winners of the $2^{\text {nd }}$ round of competitions and olympiads was downloaded. All this information is automatically displayed in the student rating.

7. The system of recording innovative projects and stakeholders. The digital space displays the information on all projects, in which a university and its structural subdivisions participate. This is the name of a project, a subdivision, stakeholders, a project manager, implementation stages, funding required, the project result and its stages, as well as the terms. All documents accompanying a project are digitized. As of 23.06.2020, 33 projects in educational units of the University were digitized. In addition, a database of stakeholders, which contains 1,956 organizations, was created. In addition to descriptive parameters, all documents accompanying cooperation with stakeholders, correspondence with them are stored in the digital space of the HEI. The participation of stakeholders in innovative projects and projects of academic mobility is reflected.

8 . The system of accounting of accommodation in dormitories. The information on students, postgraduates, the staff, and external hirers of residential premises was digitized. In total, information regarding 2,703 people was entered. In addition to descriptive information, information on rewards and punishments is displayed, the relevant documents are digitized and stored.

9. Technology of control over the execution of assignments. Meetings held at the university, orders, and instructions contain a variety of assignments for the university staff. In addition, assignments may be related to incoming correspondence and internal documents. All of them are displayed by means of the functional environment in the digital space and sent to executors. Then executors are sent a reminder of the deadlines that are due or even those already missed. Every week, the authorities are provided with information about the progress of the assignments. This is a "disciplining" element of the system. During the operation of the system, the average time of consideration of assignments decreased from 8.36 days to 1.23 days. While in the beginning, the term of execution was extended on average by 8.61 days, in June 2020, on average, the tasks were performed 3.01 days before the deadline. The percentage of timely executed tasks increased from 54.85 to 73.30 .

10. The system "Digital dean's office". The information environment, which contains the structures of the data for displaying documents about a student, his studies at the university, attendance of classes, performance, awards, rewards, and reprimands, winning competitions and olympiads, etc., was created In total, information about 15,450 students and 1,718 teachers is stored in the information environment.

11. Technology of filling the digital environment with curricula and working curricula, educational materials. The order for its implementation is as follows:

- curricula from MS Excel are imported and checked in the digital space information environment of the digital space;

- groups of students and students are divided in accordance with curricula and elective disciplines;

- working curricula and training load for departments are calculated;

- the educational load is distributed among teachers;

- teachers upload educational materials to the information environment in accordance with distributed disciplines. 
A total of 492 curricula containing 30,682 disciplines, 399 groups of students were downloaded.

12. The system of import of data from the USEBE. Information about students and teachers is imported from the USEBE into MS Excel files. The data on specialities, educational programs, students, and teachers are uploaded from MS Excel files to the information environment. At the same time, the changes in the information uploaded before are coordinated with the current data. The changes made by employees directly to the information environment are a priority and are not canceled when downloading information from the USEBE.

13. The system of educational process management. At the heart, there is the information provided to the digital space by other systems. Information on the educational load of departments and teachers is used to form the timetable of classes. Information on the number of students studying by specific curricula and the share of the educational load, which is distributed among the departments determines the normative number of teachers at a department. If the average load on the curriculum exceeds the norm, the curricula are optimized in terms of the correlation between the classroom load and students' independent work.

14. The system of conducting commercial projects of the SRD. Information on commercial projects of the SRD is displayed in the digital space. All documents accompanying projects are digitized. It has just been introduced.

15. The technology of agreement of orders and instructions. The initiator prepares an order or instruction and uploads the pdf file to the digital space. There are templates in the digital space, in what order, and who should agree on this document. Managers who have to agree on the document can: approve, return to the initiator with comments. Upon return, all prior agreements are canceled. After agreement by all participants, the document is printed out, together with the agreement sheet, which displays QR codes of the officials who agreed on the document. Then it is signed by the top manager.

16. Online learning. Moodle platform was used and is used for online learning for distance and part-time education. It has accumulated significant information base on educational materials. Due to the transition to online education of full-time students, the Google platform was additionally implemented using applications: Classroom (information environment of disciplines) and Meet (online learning). These tools were implemented on the scale of the entire university. That makes it possible to design a flexible work schedule and to use an affordable form of interaction with students under modern conditions, complicated by the COVID-19 pandemic.

Digital transformation of the NAU made it possible not only to create and implement information technologies in all areas of its activity but also to improve the processes of management, education, innovation, and economic activity. In particular, it created a virtual core of the University informatization - digital transformation office. It enabled the creation and implementation of a system of administration and control over the implementation of managerial decisions. It allowed introducing the end-to-end technology for processing and using curricula and agreement of syllabi. It made it possible to create a unified database of information about students and teachers and integrate it into all the processes of the University.

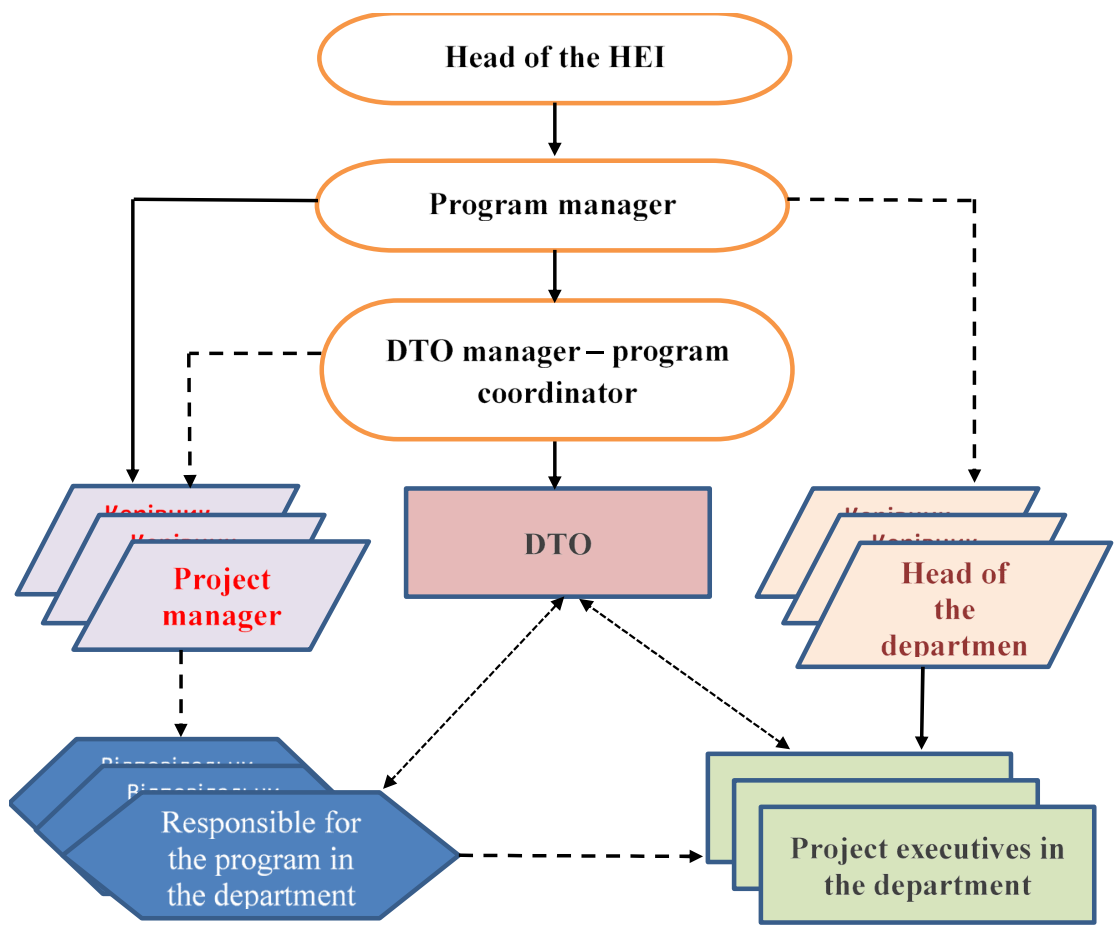

Fig. 5. Interactions in the matrix organizational structure of digitalization project management

The features of this program are that only open (free) systems and their own developments, which were automatically integrated into a single digital environment, were used in the process of creating a digital university. A unified digital space of functioning of all information systems and technologies, which includes information and functional environments created in the EDS PostgreSQL (USA), was created. All the tools are open for changes and are oriented to the NAU; the wishes of the employees were taken into consideration during their development and implementation.

\section{Discussion of the results of the development of the systems engineering concept of digitalization of higher education institutions}

The results obtained were the consequences of changing the strategy in the issues of implementation of information systems and technologies in higher education institutions. Recently, there has been a change in the key paradigm in the practice of automation of the HEI. It goes increasingly often not about the automation of solving the functional 
problems based on the use of information systems and technologies, but about the creation of digital universities based on the digital transformation of all activities. This requires a comprehensive approach to setting the organizational components of the HEI to new conditions of functioning, to the creation of digitalization technologies, and most importantly, to the effective management of all digital transformation actions through projects.

Unlike the task-scheduled approach used by the HEI to automate the solution of functional problems [2-5], the article suggests an integrative approach to the creation of the digital space of a university independent of solving functional problems. And based on it, the functional environment, which is the basis for the informatization of all parties to the activity of a higher education institution, is formed. This idea is illustrated in Fig. 1, and problems of the HEI digitalization, the decision of which is necessary for the processes of the digital transformation of higher education institutions, are shown in section 4 .

It is this vision of modern requirements for the creation of digital universities that became the basis for the creation of a systems engineering concept of digitalization of higher education institutions as a unified system of organizational, functional, and informational components. This concept is constructed by incorporating the system, process, and project approaches into a unified system of organizational, functional, and informational components.

Of course, the scenario-based approach can be added to these approaches. However, this was not done for the reason that the scenario-based approach is more consistent with the operational phase of the digital transformation when the basic tools are created and it goes about scenarios of their use. Specifically, the creation of such tools in the form of the structure and implementation mechanisms of a digital university was another objective of the research. Formulas (1) and (2) give the tool to form the structure of digital space, and Fig. 2 and Table 1 illustrate the filling of this space. In addition, the functional environment of the digital space is outlined in a sufficiently complete way. An alternative to such a solution is the traditional way of forming a digital environment through solving functional problems of the HEI. However, this leads to the disconnection of databases of different systems, and, accordingly, to the impossibility, or significant complexity of integrating such databases into a unified digital environment.

On the other hand, such a problem statement is not quite complete in terms of solving the problem of digital transformation, because it does not include the process of implementation of the actions of HEI staff on its transformation into a digital university. Although, as it follows from the results devoted to the implementation of the developed concept, these processes are implemented in practice.

In addition, within the framework of the systems engineering concept, the issue of how to use the project-based approach to the management of the creation of the digital space of the HEI was revealed. This issue was illustrated in Fig. 5,6. In addition, a verbal description of a digital transformation office, which meets the requirements of the digital transformation of the HEI, was given. Three main projects that create organizational, methodological, and technological components of the processes of digital transformation management were separated. The disadvantages include the fact that the theoretical part of the article did not reveal the filling of the projects' portfolio at the phase of application of digitalization tools of the HEI. Although the practical part contains several projects of the formation of digital space, first of all, it is the use of the electronic document flow system PrimaDoc.

The use of the systems engineering concept of digitalization of the HEI allowed not only creating a digital space of a higher education institution but also creating the tools that use this environment to solve functional problems of the HEI. The proposed systems engineering concept of digitalization of higher education institutions integrates the systematic, process-based, and project-based approaches to solve the problems of creating digital universities.

The limitations inherent in this study are related to the level of automation of the HEI activity at the current stage. If the level of automation is high, the creation of digital space will face the problem of integrating existing databases into a unified information environment. Universities that are at the initial stage of digital transformation, or in which this process has not yet begun, are more ready to implement the proposed systems engineering concept of digitalization. Another limitation is related to the existence of professional project managers in the HEI to implement the project-based approach, or with the possibility of their involvement.

The shortcomings of this study include the fact that the issue related to the implementation of the project of integration of existing (previously created) databases into a single information environment was not sufficiently studied. It is in this direction that the development of this study may continue.

Even though the issue of database integration is sufficiently studied, it is in the development of methods for managing integration projects that significant problems related to the uniqueness of such tasks may arise. After all, the creation of databases and technologies of their management can vary to a great extent in different HEI, which causes difficulties in creating universal approaches and mathematical methods of managing such projects.

\section{Conclusions}

1. The problems of digitalization within the framework of the systematic, process-based, and project-based approaches were set. These problems imply separating the main processes and projects, forming a system of their management, creating an information and functional environment of a digital university. It was shown that solving these problems will make it possible to create digital universities as a single system of organizational, functional, and information components.

2. The structure and the implementation mechanisms of a digital university were developed. In order to eliminate the shortcomings of the task-scheduled (local) approach to the digital transformation of the HEI, it is proposed to combine the systemic and process-based approaches to the creation of informational and functional environments of the digital space of the HEI. The essence of this integration is that all the processes of forming new information are based on a single system of functions of digital space. And the information obtained as a result of the implementation of functions is immersed in the single digital environment of the HEI. Based on the needs of the HEI for information to solve problems in the managerial, educational, scientific, economic, and other spheres of activity, the structures of informational and 
functional environments of the digital space of an institution of higher education were developed. The features for the classification of digitalization projects, which, unlike traditional classification methods, are in line with the separated processes in the digital space of the HEI, were proposed. This allowed presenting the implementation of processes through digitalization projects. It was proposed to use the document databases in the digital space to make it possible for the information environment to be used both to solve functional problems and to directly meet the information needs of HEI staff. According to the formulas that make it possible to determine the documents that should be uploaded to the digital space, 20 classes of documents to fill the information environments, and 11 classes of functions to be implemented in the digital space of the HEI, were specified.

3 . The concept of using the project-based approach to manage the creation of the digital space of the HEI was proposed. It was shown that effective management of digital transformation of the HEI is possible only with the successful implementation of three projects: the creation of a digital transformation office; development of a methodology for managing the projects of the HEI digitalization; creation of the information technology for digitalization project management. The feature of these projects is their interdependence because they are aimed at the formation of a unified product - the system of management of the digital transformation of the HEI (organization + methodology + technology), which provides a systemic solution to management problems in the processes of digitalization of higher education institutions. Since the organizational structure of higher education institutions is functional, it is proposed to use the matrix model of management of such projects for the implementation of digitalization projects. The peculiarities of this model, compared to the traditional matrix organization, are that the links between the subdivisions are realized not directly, but through a digital transformation office. The objectives and subject of a digital transformation office are professional support and integration of all information flows in projects of the digital transformation of the HEI.
Based on the peculiarities of the proposed matrix management model and taking into consideration the specifics of distribution of digitalization projects through implementation processes and management processes, the organizational structure, which should be used in the specific methodology of management of digital transformation project, was proposed.

Information technology of digitalization project management plays an important role in the digital transformation of the HEI. This is due to the fact that digitalization projects operate mainly with information resources. These are regulations, documents, databases, etc. That is why within the framework of the systems engineering concept of the digital transformation of the HEI, it is proposed to apply instrumental software tools for project management, such as MS Project, Primavera, etc.

4. The systems engineering concept of the HEI digitalization was practically tested at the National Aviation University (Ukraine). Unlike traditional approaches, which are based on the implementation of means of solving functional problems, the unified digital space of functioning of all information systems and technologies, which includes information and functional environments, was created at the first stage at the NAU. The unified information environment includes 92 database tables integrated into a unified system. The functional environment comprises about 200 functions of remote information processing in PostgreSQL. This approach, first of all, meets the requirements of cost-effectiveness in regard to the digital transformation of the HEI, because it eliminates any information duplication, and also makes it possible to use the same tools to solve various functional problems. Specifically, in the problems of electronic document flow, accounting of residence in dormitories, control of assignments, agreement of syllabi of disciplines and others, the unified technology of digitization, passage control, storage, and use of documents were used. In addition, this made it possible based on the uniform information environment not only to solve all functional problems but also to ensure the development of this environment through the use of arrays of new information formed in these problems.

References

1. Bocharov, B. P., Voievodina, M. Yu. (2015). Informatsiyni tekhnolohiyi v osviti. Kharkiv: KhNUMH im. O. M. Beketova, 197. Available at: https://core.ac.uk/download/pdf/78066484.pdf

2. Bogdan, M. (2019). How to Develop a University Management Software. Available at: https://kindgeek.com/blog/post/ how-to-develop-a-university-management-software

3. Fedusenko, O. V., Rafalska, O. O. (2013). Systemy upravlinnia navchalnym protsesom studentiv z rozghaluzhenoiu orhanizatsieiu dystantsiynoho navchannia u vyshchomu navchalnomu zakladi. Upravlinnia rozvytkom skladnykh system, 13, 162-165.

4. Prohramne zabezpechennia dlia vyshchykh navchalnykh zakladiv Ukrainy. Politek-SOFT. Available at: http://www.politek-soft.kiev.ua

5. Krevskiy, I., Glotova, T., Deev, M., Matyukin, S., Sheremeteva, E. (2016). Models for Cooperation Continuing Educations of Specialist with Life Cycle of E-Learning Resources and Educational Programs. Advances in Educational Technologies and Instructional Design, 258-285. doi: https://doi.org/10.4018/978-1-4666-9489-7.ch018

6. Elhoseny, M., Metawa, N., Hassanien, A. E.(2016). An automated information system to ensure quality in higher education institutions. 2016 12th International Computer Engineering Conference (ICENCO). doi: https://doi.org/10.1109/icenco.2016.7856468

7. Mora, H. L., Sanchez, P. P. (2020). Digital Transformation in Higher Education Institutions with Business Process Management: Robotic Process Automation mediation model. 2020 15th Iberian Conference on Information Systems and Technologies (CISTI). doi: https://doi.org/10.23919/cisti49556.2020.9140851

8. The 2018 digital university Staying relevant in the digital age. Available at: https://www.pwc.co.uk/assets/pdf/the-2018-digitaluniversity-staying-relevant-in-the-digital-age.pdf 
9. Bushuyev, S. D., Bushuyeva, N. S., Pokrovnitskaya, O. O. (2004). Technological maturity as strategic tool for development in project management. Upravlinnia proektamy ta rozvytok vyrobnytstva, 1 (9), 5-16.

10. Teslia, I., Yehorchenkov, O., Khlevna, I., Khlevnyi, A. (2018). Development of the concept and method of building of specified project management methodologies. Eastern-European Journal of Enterprise Technologies, 5 (3 (95)), 6-16. doi: https:// doi.org/10.15587/1729-4061.2018.142707

11. Kerroum, K., Khiat, A., Bahnasse, A., Aoula, E.-S., Khiat, Y. (2020). The proposal of an agile model for the digital transformation of the University Hassan II of Casablanca 4.0. Procedia Computer Science, 175, 403-410. doi: https://doi.org/10.1016/ j.procs.2020.07.057

12. Yehorchenkova, N. Y., Teslia, Iu. M., Khlevna, Iu. L., Kychan, O. M. (2020). Methodological aspects of creating a digital university. Bulletin of NTU “KhPI”. Series: Strategic Management, Portfolio, Program and Project Management, 1, 31-36. doi: https://doi.org/ 10.20998/2413-3000.2020.1.4

13. Unger, B. N., Gem nden, H. G., Aubry, M. (2012). The three roles of a project portfolio management office: Their impact on portfolio management execution and success. International Journal of Project Management, 30 (5), 608-620. doi: https://doi.org/10.1016/ j.ijproman.2012.01.015

14. Teslia, I., Khlevna, I. (2018). Organization of implementation of concretized methodology and information technology of project management as a unified system of project-oriented enterprise. Bulletin of the National Technical University «KhPI» Series: New Solutions in Modern Technologies, 45 (1321), 134-141. doi: https://doi.org/10.20998/2413-4295.2018.45.18

15. Abdalhamid, S., Mishra, A. (2017). Factors in Agile Methods Adoption. TEM Journal, 6 (2), 416-421. doi: http://doi.org/10.18421/ TEM62-29

16. West, D., Gilpin, M., Grant, T., Anderson, A. (2011). Water-Scrum-Fall Is The Reality Of Agile For Most Organizations Today. Forrester Research, Inc. 